\title{
Music in the mountains: creating sustainable therapy programs from short-term missions
}

\author{
Rachel Foxell ${ }^{a}$ \\ a RMT, MMusTh, BMus, GDTL, Music Therapist Teacher, Glenroy Specialist School, Australia.
}

\begin{abstract}
This field report describes the experiences of a Registered Music Therapist (RMT) living, working, and musicking ${ }^{1}$ during a short-term health mission to Northern India. Using a sustainability approach, collaboration with several local and global health organisations resulted in the development of a therapeutic music program for children with disabilities.

Disability is a complex phenomenon, and in rural areas of India, disability is viewed as a foundation for shame and exclusion. The Community-based project, Samvedna, oversees the therapy, healthcare, and education of over 100 children with a disability in remote villages and is heavily involved in disability advocacy in the area.

Sustainable programs are more effective for individuals and communities in both the short and long term. RMTs and other health professionals can be instrumental in setting up sustainable programs, such as teaching specific skills and knowledge to local teams, provided there is thorough preparation and ongoing collaboration to determine the priorities and expectations of the program.
\end{abstract}

In a remote village not accessible by road, a little girl with an intellectual disability lives with her grandmother. They have come with their neighbours to their village leader's house to see Doctor Nathan and his visiting friends. Sakshi is non-verbal and appears to have little understanding or interest in the conversation around her. Her parents do not want her. Our translator relays her grandmother's words: They have said, in her hearing, that it would be better if she were dead. How can I respond? It is my third day in India.

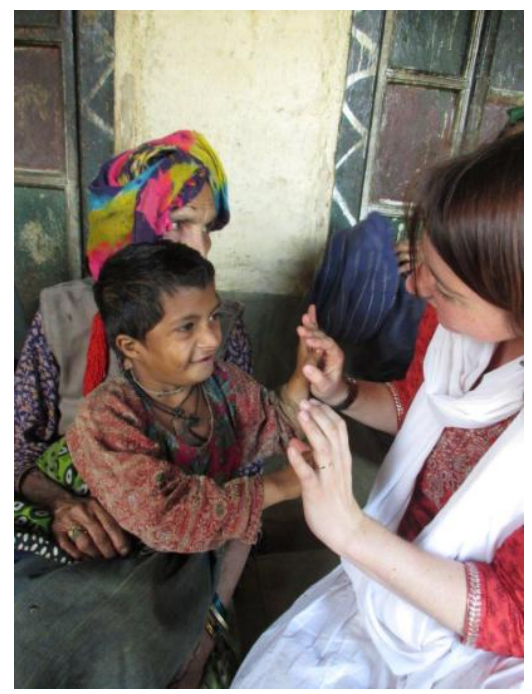

Nov 2015. Christian Journal for Global Health, 2(2):64-68. 
Disability is a complex phenomenon, reflecting the interaction between features of a person's body and features of the society in which he or she lives. Disability is not just a health problem or a social problem, but describes the way a person's physical impairment relates to their society, environment, and the political landscape. ${ }^{2}$ Overcoming the difficulties faced by people with disabilities may involve medical interventions to correct or reduce impairment, but should equally require interventions to remove environmental and societal barriers. ${ }^{2-4}$

In India, particularly in rural and remote regions, people with a disability can be considered worthless individuals and may be abandoned by their families or treated as a lesser part of the family unit. Traditional Hindu culture places great shame on people who have a disability, whether through accident, illness, or a disability from birth. People with a disability struggle to be accepted into their communities, make marriages, and participate in daily village life. When a child is born with a disability, both mother and child are blamed, with the implication that the disability has been caused by a $\sin$ committed in a past life.

In 2014, my husband and I volunteered for two months for the Emmanuel Hospital Association (EHA) India, a network of 20 hospitals in Central and Northern India. EHA hospitals also support a number of CommunityBased Rehabilitation (CBR) projects such as disability support and advocacy, mental health, and work in slums and low-caste rural villages. Samvedna, which means "empathy," is a CBR project working to establish attitudes of inclusiveness in families and village communities through spreading the message that Jesus loves every person regardless of their abilities, using both words and actions. Samvedna, established four years ago, oversees the education, healthcare, and ongoing therapy of over a hundred children with disabilities across dozens of remote mountain villages in the foothills of the Himalayas, about $350 \mathrm{~km}$ north of New Delhi.
As an Australian Registered Music Therapist (RMT), and special education teacher, my goal was to create a sustainable music therapy program for the Samvedna project. ${ }^{5}$ However, good crosscultural aid or development work does not simply implant one way of working straight into another culture. ${ }^{6}$ In addition to an awareness of specific communication and cultural differences between the foreigner and the local community, there are always complex layers of power dynamics at play in any cross-cultural interaction. ${ }^{7-9}$ Significant preparation is necessary for any cross-cultural work to be effective in both the short- and longterm. ${ }^{10-11}$ One of the critiques of short-term health missions (STHMs) is that they do not adequately meet the needs of a community or address complex health problems of the local area. STHM workers often do not fully consider the impact of their initial presence and inevitable absence on the continuing lives of those they have come to "help." Serious implications may arise, resulting in continued unequal partnerships between hosts and visiting professionals and also negative consequences for patients and communities. ${ }^{10}$

Conversely, programs that work in collaboration with local stakeholders through fostering equal partnerships of learning and knowledge sharing and actively following up through training and resource provision have been able to generate sustainable, positive results for locals. $^{10-11}$ In this way, sustainability and collaboration are intertwined, the success of one being dependent on the other.

RMTs and other health professionals working cross-culturally are well equipped to create sustainable music therapy programs provided there is:

- Ongoing collaboration with the community regarding the aims and purpose of the project.

- Adequate time for development.

- Realistic expectations regarding the outcomes of the project. ${ }^{11}$

Knowing my time on the ground was limited, it was important to develop good relationships with the stakeholders, both individuals and 
|organisations, in the months before my arrival. Rather than set my own priorities for the mission, I wanted these to evolve naturally from collaborative discussions with the Samvedna staff team. Over time, it became clear that one of my main aims during the four-week placement would be a plan for training volunteers and staff in therapeutic music skills. However, as the Samvedna volunteers and families would be the ones actually participating, their buy-in was crucial to the success of a sustainable program.

The buy-in process formed three stages over five weeks (the first two overlapping by a week or more):

1. Listening to the community's needs

2. Demonstrating and teaching skills

3. Facilitating local ownership of the program

\section{Listening}

The staff, volunteers, and families at Samvedna have had regular contact with foreign visitors. When my husband and I arrived in the village of Dhana, a group of about 50 people gathered in the centre to welcome us and tell their stories. This pattern continued throughout the week as we travelled to different villages in the region, visiting families and listening.

Being a woman also opened unexpected doors for me. Three women, mothers of children with a disability, had refused to speak during a mixed meeting, despite urging from the Samvedna co-ordinator. During a chai-break outside, they immediately beckoned me over. In three-way translation (Garwhali-Hindi-English and back), the women shared with me their isolation and the hard, constant work of 24-hour care with no help from neighbours or family. Why did they choose to hold back in the group? It is normal for women to remain silent in mixed meetings, perhaps due to the gender inequality prevalent in rural areas; but, I think it is possible that they wanted to hold power over their stories until they felt they could trust me with them.

\section{Demonstrating and teaching skills}

Whenever I met with families or visited learning centres, I made a point of sitting with the children and doing simple, child-led vocal or percussive dialogue. When possible, I demonstrated and explained how I worked with rhythm and songs in Australia. This ground work, coupled with my willingness to listen and learn, helped the volunteers to buy-in to the concept of music therapy and show interest in learning the skills I offered. The resulting three-day workshop co-facilitated with colleagues from The Music Therapy Trust (TMTT) in Delhi was a hands-on approach to learning therapeutic music skills. ${ }^{12}$ By the end of the workshop, the volunteer team had come up with nine principles for therapeutic music-making that they could apply straight away to their own practice, such as: letting the child lead the interaction; engaging on the child's level; using the child's name as a rhythm or melody as the basis for interaction.

\section{Local ownership of the project}

After the final session of the workshop, three volunteers were appointed Music Ambassadors, representatives who felt confident enough in their new skills to help others problem-solve any issues and contact TMTT with any issues. In the week following the workshop, volunteers who had returned to their village centres to practise their new skills, enthusiastically reported the children's increased engagement through music. At this stage, the volunteers felt real ownership of their new skills and knowledge, which spoke volumes to me about the potential of this program to continue long after I left India. When I last heard from the Samvedna co-ordinator, he told me the volunteers are still using music weekly in their learning centres.

When considering cross-cultural interventions in music therapy, or any health profession, it is vital to consider and plan for a sustainable outcome in collaboration with local stakeholders. Sustainable programs are more effective for individuals and communities in both 
the short- and long-term. RMTs and other health professionals can be instrumental in setting up sustainable programs, such as teaching specific skills and knowledge to local teams, provided there is thorough preparation and ongoing collaboration to determine the priorities and expectations of the program.

As I sat there next to Sakshi, I realised something: although we had certainly spent time talking about her, not one person had spoken to her that whole afternoon. So I began to gently seek eye contact and invite her into a wordless vocal dialogue. It took just a few minutes for her to completely transform. In her village, she had been known as alternately withdrawn and aggressive. But in reality, she was eager to connect with those around her and had never before had an opportunity. Witnessed by her neighbours, her vocal sounds during our dialogue were loud, insistent, and full of joy. This interaction has changed her life, forever.

\section{References}

1. Small, C. Musicking: the meanings of performing and listening. Middletown, CT: Wesleyan University Press; 1998.

2. WHO: Health topics: Disability [Internet]. Geneva: World Health Organization; c2015 [cited 2015 August 29] Available from:

http://www.who.int/topics/disabilities/en/.

3. Anastasiou D, Kauffman J. Disability as cultural difference: implications for special education.

Remedial and Special Education. 2012;33(3): 139

|149. http://dx.doi.org/10.1177/0741932510383163.
4. Rickson D. The relevance of disability perspectives in music therapy practice with children and young people who have intellectual disability. Voices: A World Forum for Music Therapy. 2014;14(3). http://dx.doi.org/10.15845/voices.v14i3.784

5. Australian Music Therapy Association. What is music therapy? [Internet]. Melbourne, Australia; c2012 [cited 2015 September 20]. Available from:

http://www.austmta.org.au/content/what-music-therapy

6. Elmer D. Cross-cultural servanthood: serving the world with Christ-like humility. Madison, WI: InterVarsity Press; 2006.

7. Bolger L. Music therapy and international development in action and reflection: a case study of a women's music group in rural Bangladesh. Australian Journal of Music Therapy. 2012;23: 22-39.

8. Mahoney E. Multicultural music therapy: an exploration. Voices: A World Forum for Music Therapy. 2015;15(2).

http://dx.doi.org/10.15845/voices.v15i2.844

9. Brown J. Towards a culturally centred music therapy practice. Voices: A World Forum for Music Therapy. 2002;2(1). http://dx.doi.org/10.15845/voices.v2i1.72

10. Swanson R, Thacker B. Systems thinking in shortterm health missions: a conceptual introduction and consideration of implications for practice. Christian Journal for Global Health. 2015;2(1): 7-22. http://dx.doi.org/10.15566/cjgh.v2i1.50

11. Bolger L, Skewes McFerran K. Demonstrating sustainability in the practices of music therapists: Reflections from Bangladesh. Voices: A World Forum for Music Therapy. 2013;13(2).

http://dx.doi.org/10.15845/voices.v13i2.715

12. The Music Therapy Trust. New Delhi, India; c2013 [cited 2015 September 18]. Available from: http://www.themusictherapytrust.com/index.htm

Competing Interests: None declared.

Acknowledgments: With thanks to EHA India; the Samvedna staff, families and volunteers, and The Music Therapy Trust, New Delhi.

Correspondence: Rachel Foxell rachel.foxell@live.com

Cite this article as: Foxell R. Music in the mountains: creating sustainable therapy programs from short-term missions. Christian Journal for Global Health (Nov 2015), 2(2): 64-68. 
(C) Foxell $\mathrm{R}$ This is an open-access article distributed under the terms of the Creative Commons Attribution License, which permits unrestricted use, distribution, and reproduction in any medium, provided the original author and source are properly cited. To view a copy of the license, visit http://creativecommons.org/licenses/by/3.0/

www.cjgh.org 